\title{
REVISIÓN DE LIBROS
}

\author{
COME NTARIO AL LIBRO \\ "MAESTRO: Greenspan's Fed and the American Boom" \\ de Bob Woodward* \\ Simon and Schuster, 2000
}

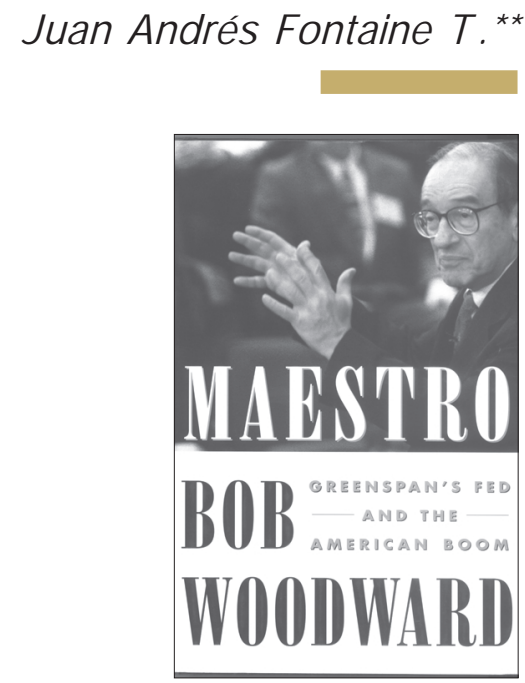

\section{EL FACTOR HUMANO En LA POLÍtica MONetaRia}

Recomiendo leer "Maestro", el relato del célebre periodista Bob Woodward sobre la gestión de Alan Greenspan, a quienes se interesan en la política monetaria tal como ella se hace en el mundo real.

No se trata, por cierto, de un análisis riguroso del desempeño de Greenspan a la cabeza del Banco de la Reserva Federal (Fed) durante los últimos y excepcionales 16 años. El relato de Woodward es periodístico, exagera lo anecdótico y evita adentrarse en profundidades. A ratos parece novelesco: Estados Unidos figura repetidamente amenazado por derrumbes bursátiles, descalabros financieros, excesos fiscales y violentas fluctuaciones de las expectativas, pero es siempre alejado del abismo gracias a unos pocos y diestros puntos menos o más en las tasas de interés. Para el economista inquieto, la pregunta obvia es cómo un instrumento tan sutil logra tanto poder, pero no se encuentra en el libro la respuesta. Tampoco satisface éste la interrogante, interesante desde la perspectiva biográfica, de cómo sobrevive el protagonista de la historia a tanta presión sicológica. Ciertamente no ayuda mucho el que, según sostiene, Greenspan procure relajarse en sus ratos de ocio resolviendo problemas de cálculo diferencial. Sin embargo, pese a sus limitaciones, el libro transmite bien la atmósfera de ansiedad y responsabilidad que se respira en esa torre de control de las economías capitalistas que son los bancos centrales.

Greenspan es en verdad un enigma. Un economista sin mayor trayectoria académica, aunque con vasta experiencia en el mundo real como consultor y director de empresas, que desafía en los hechos buena parte del consenso profesional de cómo debe administrarse la política monetaria. Un connotado simpatizante del Partido Republicano, de participación activa en la campaña presidencial de Richard Nixon y en el gobierno de Gerald Ford, que llega a la presidencia del Banco de la Reserva Federal en las postrimerías de la administración de Ronald Reagan, mantiene una tensa relación con su sucesor republicano George Bush (padre) y alcanza el apogeo de su efectividad y prestigio bajo el gobierno demócrata de Bill Clinton. En su juventud ha seguido las aguas de la intelectual liberal Ayn Rand y se considera a sí mismo un libertarian; sin embargo, desde el Fed practica una buena dosis de intervencionismo discrecional en materia de política monetaria. La ausencia de dogmatismo y la agilidad mental parecen ser sus atributos principales. Y a diferencia de tantos otros pragmáticos intervencionistas, lo hace bien: y cosecha aplausos de moros y cristianos. Con razón Milton Friedman se declara perplejo: “ ¿Tiene Alan Greenspan una percepción sobre los movimientos de la economía que otra gente no tiene?", se ha preguntado.

\footnotetext{
La edición de bolsillo, del 2001, incluye un capitulo final en que da cuenta del atentado del 11 de septiembre y el fin del boom.

${ }^{* *}$ Consultora J.A. Fontaine y Asociados.
} 


\section{¿Independencia política?}

Un candidato obvio para explicar el buen desempeño de Greenspan es el carácter independiente del Fed. Presumiblemente, ello le da credibilidad antiinflacionaria incluso a las acciones monetarias más heterodoxas.

Hay pruebas de que, efectivamente, el Fed es un organismo autónomo. El antecesor de Greenspan, Paul Volker, es un "conocido demócrata" —en las palabras de Woodward-que es "renominado" por el republicano Ronald Reagan debido al sólido prestigio que ha ganado en la batalla contra la inflación a comienzos de los años ochenta. El republicano Greenspan es nombrado más tarde por Reagan, y mantenido en su cargo por los dos presidentes siguientes, el republicano George Bush (padre) y el demócrata Bill Clinton, porque el mercado lo pide. Greenspan es suficientemente independiente como para irritar a su correligionario Bush con su insistencia en mantener altos los intereses durante 1989-1990, con la consiguiente recesión y fracaso electoral dos años más tarde. Con Clinton en la Casa Blanca, Greenspan trabaja bien.

Woodward atribuye a Greenspan el haber convencido a Clinton - con la valiosa ayuda de su Secretario del Tesoro, Robert Rubin - a impulsar un significativo ajuste fiscal a comienzos de su mandato. El argumento - tan familiar para nosotros es que dicho ajuste permite una reducción no inflacionaria de las tasas de interés, particularmente las de largo plazo. Clinton logra aprobar su paquete fiscal, es felicitado por Greenspan y premiado con un recorte en la tasa de política monetaria. El ajuste fiscal es bien recibido por los mercados, provocando una fuerte reducción en las tasas de largo plazo y pavimentando el camino para una expansión sin precedentes de la inversión, el producto y los valores bursátiles.

Sin embargo, no puede atribuirse la efectividad de Greenspan solamente a su independencia política. Bajo Reagan y Bush (padre), el Fed es criticado en voz alta por las más prominentes autoridades, siempre bajo la acusación de descuidar el desempleo y el crecimiento $\mathrm{y}$, con alguna tardanza, la autoridad monetaria concede. Por ejemplo, Greenspan es percibido como demasiado inclinado a agradar a Bush durante 1991, cuando éste demora su renominación a la espera de nuevos recortes de tasas, funcionales a su intento de reelección en 1992. Cuando finalmente Greenspan es reconfirmado, el New York Times editorializa: "El señor Greenspan conoce su oficio, pero hay dudas sobre su independencia". Ante ese grave comentario nadie rasga vestiduras por la institucionalidad amenazada.

El corazón republicano de Greenspan también late fuerte cuando asume George Bush (hijo) el sillón presidencial. No trepida en proclamar su entusiasmo por el intrépido recorte de impuestos que propone la nueva Administración el año 2000. Woodward que debe consignar el hecho en un "post scriptum", agregado a la edición de bolsillo- no puede disimular su desencanto con el otrora paladín del ajuste fiscal.

Aunque, de acuerdo con el relato de Woodward, Greenspan es el protagonista indiscutido, con diestro manejo de las decisiones colectivas del directorio del Fed, sus restantes miembros también juegan un rol importante. Gerald Corrigan, entonces presidente del Fed de New York, es quien verdaderamente conjura el peligro de una crisis mayor tras el derrumbe bursátil de 1987. Greenspan, recién nombrado, aparece más confundido y vacilante de lo que la leyenda contó posteriormente acerca de ese heroico rescate. El episodio del Long Term Capitol Management Fund es semejante, con el sucesor de Corrigan, Bill Mc Donough, jugando ahora el papel estelar.

En cambio, el equipo de planta del Fed figura menos en la historia de Woodward. El comité de Política Monetaria del Fed oye sus proyecciones, pero actúa por instinto. Lo conforman siete gobernadores elegidos por el Presidente de la Nación, previa aprobación del Senado, y cinco presidentes de los Fed regionales (de entre los doce existentes). Sus opiniones y votos cuentan. Los gobiernos maniobran incesantemente para influir en ellos y calibran sus nombramientos para inclinar la balanza a favor de políticas expansivas. Greenspan maniobra hábilmente para neutralizar la influencia de sus vicepresidentes, como David Mullins bajo Bush y Alan Blinder bajo Clinton, que parecen haber recibido del gobierno el encargo de contrapesar los instintos antiinflacionarios del jefe del Fed. Un intento de Clinton por nombrar a Felix Rohatyn, empresario entusiasta de la "nueva economía" y 
más tolerante con la inflación, naufraga tras diestra artillería de prensa, orquestada aparentemente por el Maestro en persona. Conclusión: el Fed es una institución independiente y respetada, pero habas se cuecen también allí.

El retrato que pinta Woodward es el de un maestro en la administración de los comités del Fed, de su relación con el gobierno y de su manejo con la prensa. Esto es, un gran político. Pero, que a diferencia de quienes suelen corresponder a ese perfil, actúa con un horizonte de largo plazo. Maniobra discrecionalmente con las tasas de interés y evita comprometerse públicamente con metas específicas de expansión monetaria o de inflación, pero es innegable que el único norte de su gestión es contribuir al crecimiento del producto y del empleo mediante la estabilidad de precios. La independencia del Fed ha de haberle ayudado en ese cometido, no siempre grato a los intereses políticos.

\section{¿Buenos reflejos?}

Gregory Mankiw, de la Universidad de Harvard, ha tratado de responder la interrogante de Friedman. ${ }^{1}$ Junto con documentar el desempeño excepcional de la economía norteamericana durante los noventa (crecimiento alto y estable, inflación baja y estable), atribuye el éxito a una virtuosa combinación de (a) buena suerte y (b) una inusual velocidad de reacción por parte de Greeenspan. La buena fortuna se demuestra en que los noventa tuvieron menos shocks de oferta (precios del petróleo, de alimentos) que las décadas anteriores, y éstos son conocidamente más difíciles de neutralizar con la política monetaria que los provenientes de la demanda. Adicionalmente, la productividad mejora ostensiblemente, y abre la posibilidad de un crecimiento económico rápido sin riesgo inflacionario. Pero el recuento de Woodward deja una imagen diferente: Greenspan ha debido enfrentar violentos movimientos bursátiles (el derrumbe de 1987, la burbuja de las "puntocom" de fines de los noventa, el pánico del 11 de septiembre pasado) y graves descalabros financieros (la quiebra de las Asociaciones de Ahorro y Préstamos, la caída del Long Term Capital Management Fund, las crisis mexicana, asiática y rusa), los cuales bien pudieron haber descarrilado la marcha del boom norteamericano. Por otra parte, la revolución tecnológica y su impacto sobre la productividad fueron sin duda una bendición, pero sus efectos macroeconómicos pueden ser muy desestabilizadores si dan lugar a aumentos desorbitados del gasto o enturbian la visión sobre el verdadero crecimiento potencial de la economía. En definitiva, con la proposición (a) de Mankiw, que atribuye el éxito sólo a la buena suerte, ocurre lo que suele verse también cuando se trata de justificar fracasos: se funda en una selección sesgada de antecedentes, que incluye sólo los que a priori se sabe que validan la hipótesis.

Nos queda la proposición (b) de Mankiw: nuestro héroe habría mostrado reflejos inusualmente buenos. Específicamente, Mankiw obtiene una función de reacción para la tasa de interés de política monetaria de EE.UU. (TPM), basada en la tasa de inflación subyacente acumulada en los últimos doce meses $(p)$ y la tasa de desempleo desestacionalizada $(u)$, a saber:

$$
T P M=8.5+1.4(p-u),
$$

la cual representaría con razonable precisión econométrica las decisiones del Fed de Greenspan. Mankiw destaca que el coeficiente de la inflación sea mayor que la unidad, sugiriendo que el éxito del Maestro se debe a que ha sabido responder con prontitud a un alza (baja) de la inflación con un alza (baja) de la tasa de interés real y no meramente la nominal. Desde luego, ese hallazgo no es teóricamente sorprendente y es compatible con la práctica de la política monetaria chilena entre 1985 y 2001.

En cambio, lo que sí parece intrigante es que una estrategia monetaria tan estrechamente ligada al "último dato" de inflación y desempleo haya resultado exitosa. Con expectativas racionales ello no habría sido posible. Pero incluso sin recurrir a ese afamado paradigma, la vieja constatación de que la política monetaria actúa con "rezagos largos y variables" ya habría recomendado abstenerse de una estrategia tan corta de vista. ¿Cómo, entonces, Greenspan obtiene tanto éxito?

La interpretación de Mankiw en cuanto a la velocidad de reacción del Maestro encuentra en el relato de Woodward abundante evidencia. Son numerosas las ocasiones en que, de acuerdo a su versión, las decisiones del comité de política monetaria del Fed terminan

Ver Mankiw, G. (2001). La cita de Friedman es de él. 
gobernadas por el "último dato", sea de inflación, de desempleo o incluso en la percepción sobre el ritmo de actividad extraída por el incansable Greenspan de alguna conversación telefónica o de cóctel. Hay, sin embargo, otras instancias, en las cuales su presidente recomienda no actuar, aun cuando las tendencias recientes de los indicadores parecieran aconsejarlo. Su maestría parece radicar precisamente en saber discriminar la paja del trigo, en medio del torrente de información económica que pasa ante sus anteojos.

Volviendo a la pregunta de Friedman, ¿sugiere Woodward que Greenspan sabe más? Sus reflejos son rápidos, pero su capacidad predictiva es tan limitada como la de cualquier otro mortal. Declara en febrero de 1994 que no recuerda una economía más balanceada que la de entonces y un par de semanas más tarde sube la tasa a 9.75\% (la cúspide del período). En julio de 1991 — cuando acaba de ser nominado para su segundo período - proclama terminada la recesión de entonces y se dice confiado en una "sólida recuperación". Pero, lejos de ello, la desaceleración se torna vertiginosa en los siguientes doce meses y las tasas deben ser recortadas desde 5.75 a 3.0\%. En junio de 1995 está "muy satisfecho" con el desempeño de la economía (la TPM ha sido elevada a $6 \%$ a comienzos de año); y un mes más tarde se decreta una rebaja de $0.25 \%$ para prevenir una desaceleración (le siguen luego otras). En diciembre de 1996, el Maestro se alarma con el auge bursátil (el Dow Jones ha subido 22\% ese mes y está en 6000 puntos) y alerta sobre una posible "exuberancia irracional" de los mercados. Entonces parece escéptico acerca de la "nueva economía" y su capacidad de ofrecer altísimo crecimiento sin inflación. Pero, en 1999-2000 —con la economía creciendo entre 4 y $5 \%$ y el Dow Jones bordeando los 12000 puntos - ha depuesto sus críticas y aviva a las barras bravas de la nueva economía. Entre tanto, sus rápidas reacciones - esto es, rebajas de tasas-, ante el riesgo de un derrumbe bursátil, han otorgado al mercado la falsa seguridad de que Greenspan garantiza a la Bolsa una suerte de "precio de sustentación" (el llamado "Greenspan put”). ¿Cómo sorprenderse entonces de la exuberancia irracional?

\footnotetext{
Ver Barro R. J. (1976).
}

\section{El Rol del liderazgo}

El Maestro no posee nada parecido a ese "conocimiento perfecto" que suelen suponer los modelos de texto. Pero es rápido para reaccionar ante la nueva información, y es creíble. La imagen que pinta Woodward es la de un infatigable investigador, examinando, lupa en mano, cada nueva cosecha de datos, a fin de detectar hasta el más leve indicio de alguna tendencia desestabilizadora. En esa tarea lo ayuda su larga experiencia en la economía del mundo real, su excepcional familiaridad con el detalle de las estadísticas y su ductilidad para reaccionar ante nuevas evidencias, ajeno por entero a la rigidez que suelen mostrar los economistas formados en las lides académicas.

Destaca luego su capacidad de traducir el diagnóstico en un mensaje certero al mercado a través de los movimientos de la TPM, generalmente en dosis de 0.25 puntos porcentuales, pero a veces también de $0.50 \%$ e incluso $0.75 \%$. Greenspan logra así un diálogo fructífero con el mercado. Lee en los datos y en los precios de mercado (por ejemplo, las tasas de largo plazo) las tendencias y las expectativas. Luego las confirma o no, las refuerza o al contrario las desarma, con una movida inesperada, hablando el idioma conciso pero contundente de los ajustes de la TPM. De vez en cuando acompaña el mensaje con declaraciones y anuncios, como por ejemplo, la advertencia de que el Fed "se inclina por" elevar la $T P M$ en un futuro próximo. El Fed de Greenspan es mucho más transparente que el de sus antecesores y su presidente es extremadamente cuidadoso con sus dichos. Aun así, la opinión de Woodward es que muchas veces sus palabras son deliberadamente opacas.

Es a través de sus acciones de política monetaria que Greenspan habla claro y el mercado le entiende. Pero, ¿por qué le cree? O, todavía más crudamente, ¿por qué le presta atención? La respuesta apunta probablemente al corazón del rol de la política monetaria. Si los precios son flexibles y las expectativas se forman de manera racional, sólo hay un rol para la política monetaria cuando hay asimetrías de información, como lo planteara la importante y no siempre destacada - contribución de Robert Barro. ${ }^{2}$ La asimetría de información suele modelarse de manera relativamente artificial — suponiendo al banco central conocer los shocks con antelación- 
pero en el mundo real es probable que surja del talento de algunos en el seguimiento del ciclo económico. La distribución de las habilidades en esta materia no tiene por qué ser uniforme y la destreza puede ser acrecentada con la especialización. Un banco central conducido por alguien talentoso opera como si tuviese una ventaja de información respecto del mercado. Es más, si tras algunos aciertos el público pasa a confiar en esa capacidad, adquiere la posibilidad de liderar las expectativas.

Un banco central es un buen lugar para alojar a un líder, pero no el único. No todos los banqueros centrales están ungidos de esa capacidad. Que un líder esté a cargo de la política monetaria es particularmente eficiente. Ve primero, porque a él el mercado le ha delegado esta tarea; y transmite un mensaje creíble, porque tiene reputación de vidente. Esa capacidad de pastorear las expectativas es la que puede denominarse el "factor humano" en la política monetaria. A la teoría económica no le resulta cómodo detenerse en el rol del liderazgo, porque prefiere no contaminar sus modelos con aspectos sicológicos. Pero, una vez aceptada la importancia de las expectativas, éstos parecen inevitables. Y no es difícil convenir en que ni las expectativas adaptativas ni las racionales constituyen procesos sicológicos demasiado convincentes. ¿Por qué no pensar que los mercados, en la difícil tarea de escudriñar el futuro, también recurren a la especialización del trabajo y terminan confiándose al "olfato" de unos pocos elegidos? En el mundo real, son numerosas las instancias en que aparece claro el liderazgo ejercido por uno que otro esclarecido ministro de hacienda o banquero central.

Greenspan parece tener capacidad de liderazgo y disfrutarlo: cuando lo designaba para su cuarto período, Bill Clinton agradece conceptuosamente su gestión y disposición de seguir sirviendo al país. “iOh no!”, responde el Maestro, "Este es el mejor oficio del mundo. Es como comer maní. Uno empieza, sigue, y nunca se cansa". Pero, desgraciadamente no hay maní para siempre. Greenspan cumplirá los setenta y siete años el 2003, cuando expire su mandato. ¿Hay un nuevo Maestro en la fila?

\section{Moraleja}

No es cierto que toda política monetaria activista sea ineficaz o, peor aún, contraproducente. Un banco central independiente, conducido por un piloto alerta, ágil y creíble puede hacer mucho bien. Pero la tentación de dejarse llevar por objetivos de corto plazo y el riesgo de error son significativos. La importancia de someter la política monetaria a reglas preestablecidas es por eso válida, aun después de Greenspan. Él mismo es probable que haya cometido varias equivocaciones, incluida quizá una excesiva dosis de estimulantes tras el 11 de septiembre, aunque sus consecuencias no sean todavía visibles. El oficio de Maestro es, entonces, extremadamente arduo y riesgoso. Cuidado con los imitadores criollos.

\section{REFERENCIAS}

Barro R. J. (1976). "Rational Expectations and the Role of Monetary Policy." Journal of Monetary Economics 2(1): $1-32$.

Mankiw, G. (2001). "U.S. Monetary Policy During the 1990s." Harvard Institute of Economic Research, Discussion Paper No 1927, agosto. 